\title{
Correction to: The incidence of venous thromboembolism in critically ill patients with COVID-19 compared with critically ill non-COVID patients
}

\author{
Sean Boyd ${ }^{1} \cdot$ Ignacio Martin-Loeches ${ }^{1,2,3}$
}

Published online: 24 January 2022

(c) The Author(s), under exclusive licence to Royal Academy of Medicine in Ireland 2022

\section{Correction to: Irish Journal of Medical Science (1971)-(2021) 190:1317-1320 https://doi.org/10.1007/s11845-020-02503-0}

In the "Discussion" section of the article the statement: "In our study, we noted that aPTT levels were significantly elevated in the COVID group, compared to the other groups, who were within normal range." should be corrected to "In our study, we noted that aPTT levels were significantly higher in the COVID group, compared to the other groups. Yet, the COVID group was still within the normal range. The other groups were below the normal range."

Publisher's Note Springer Nature remains neutral with regard to jurisdictional claims in published maps and institutional affiliations.

The original article can be found online at https://doi.org/10.1007/ s11845-020-02503-0.

Sean Boyd

sean.boyd@ucdconnect.ie

1 Multidisciplinary Intensive Care Research Organization (MICRO), St James's Hospital, Dublin, Ireland

2 Trinity College Dublin, Dublin, Ireland

3 Pulmonary Intensive Care Unit, Respiratory Institute,

Hospital Clinic of Barcelona, IDIBAPS, University

of Barcelona, 08036 CIBERes, Spain 